\title{
IMPLEMENTASI METODE K-MEANS CLUSTERING UNTUK PENENTUAN JENIS KOMENTAR PADA TWEET PSSI
}

\author{
Muhammad Ali Rheza ${ }^{1}$, Farindika Metandi ${ }^{2}$ \\ ${ }^{1}$ Program Studi Teknik Informatika Multimedia, Politeknik Negeri Samarinda \\ ${ }^{2}$,Teknik Informatika, Politeknik Negeri Samarinda \\ *Email: ali.rheza@gmail.com ${ }^{1)}$, farindika@polnes.ac.id ${ }^{2)}$
}

\begin{abstract}
Abstrak - Berita tentang Persatuan Sepakbola Seluruh Indonesia (PSSI) sedang ramai di perbincangkan. Perbincangan tersebut bisa berasal dari salah satu media sosial yaitu Twitter. Twitter berisi informasi, pesan, dan komentar dari pengguna satu ke pengguna lain. Jenis komentar twitter terhadap PSSI sangat beragam, Terdapat jenis-jenis komentar, contohnya yaitu jenis komentar ironi, komentar sinisme, dan komentar sarkasme. Data yang digunakan pada penelitian ini adalah data Komentar dari pengguna Twitter yang membahas tentang PSSI. Penelitian ini bertujuan untuk mengetahui jenis komentar terkategori komentar ironi, sinisme dan sarkasme dengan Metode K-means Clustering. Dari proses perhitungan menggunakan metode K-Means Clustering menghasilkan Kelompok jenis komentar sinisme pada cluster 1 sebanyak 20 data, kelompok jenis komentar sarkasme pada cluster 2 sebanyak 3 data dan kelompok jenis komentar ironi pada cluster 3 sebanyak 27 data.
\end{abstract}

Kata Kunci: PSSI, K-Means, Clustering

\section{Pendahuluan}

Berita tentang Persatuan Sepakbola Seluruh Indonesia (PSSI) selalu ramai di perbincangkan di negeri ini seperti PSSI tidak memperpanjang kontrak pelatih Luis Milla, konflik pelatih Shin Tae Yong, dan kegagalan target juara timnas di piala AFF. Kegagalan Timnas Indonesia di piala AFF ini bisa dipengaruhi beberapa hal, seperti pemilihan pelatih secara mendadak, kemudian pelatih terpilih pun tak bisa leluasa menentukan pemain ketika liga tetap bergulir, dan adanya mafia bola yang terlibat pengaturan skor di sepakbola Indonesia.

Beberapa berita tersebut bisa berasal dari salah satu media sosial yaitu Twitter. Twitter adalah salah satu media sosial dengan jutaan pengguna, yang memungkinkan penggunanya untuk mengirim dan membaca pesan berbasis teks hingga 280 karakter. Twitter berisi informasi, dan komentar dari pengguna satu ke pengguna lain.

Komentar adalah ulasan atau tanggapan atas berita, pidato dan sebagainya dengan tujuan untuk menjelaskan dan menerangkan. Komentar di sampaikan secara lisan atau tulisan. Pada sebuah komentar terdapat majas atau gaya bahasa [1].

Majas disebut gaya bahasa. Gaya atau khususnya gaya bahasa dikenal dalam retorika dengan istilah style. Gaya bahasa juga memungkinkan kita dapat menilai pribadi, watak, dan kemampuan [2].

Terdapat jenis-jenis komentar berdasarkan gaya bahasa, yaitu jenis komentar ironi yang menyatakan makna bertentangan dengan maksud berolok-olok. Komentar ironi biasanya digunakan untuk menyatakan sindiran secara halus [3]. Kemudian jenis komentar sinisme adalah jenis komentar yang di artikan sebagai suatu sindiran yang berbentuk kesangsian yang mengandung ejekan. Komentar sinisme cenderung lebih keras dari pada ironi [2]. dan jenis komentar sarkasme adalah jenis komentar yang lebih kasar dari ironi dan sinisme. Komentar sarkasme adalah sindiran yang paling kasar dalam percakapan sehari harihari, sarkasme digunakan untuk mengejek, menghina dan menyumpah yang di tunjukan kepada seseorang [3].

Clustering merupakan suatu metode untuk mengelompokkan data yang memiliki kemiripan karakteriktik antara satu data dengan data yang lain. Clustering adalah salah satu metode data mining yang bersifat tanpa arahan (unsupervised), metode ini diterapkan tanpa adanya latihan dan tanpa adanya guru (teacher) serta tidak memerlukan target output. Clustering yang digunakan dalam pengelompokan data terbagi menjadi dua, yaitu hierarchical clustering dan nonhierarchical clustering [4].

K-Means adalah salah satu metode data clustering non-hirarki yang mempartisi data ke dalam bentuk satu atau lebih cluster, sehingga data yang memiliki karakteristik yang sama dikelompokkan dalam satu cluster yang sama dan data yang memiliki karakteristik berbeda dikelompokkan ke dalam kelompok lain [4].

Dari penjelasan yang telah di uraikan di atas penulis dapat menggunakan metode $K$-Means Clustering untuk pengelompokan jenis komentar berdasarkan jumlah kalimat positif dan negatif di setiap data komentar, dengan bertujuan untuk mengetahui seberapa banyak jenis komentar ironi, komentar sinisme, dan komentar sarkasme.

\section{MetOdE}

Tahapan dalam penelitian ini dapat ditunjukan seperti pada Gambar 1. 
a. Riset awal, Sebelum melakukan penelitian terlebih dahulu penulis harus mempelajari segala hal yang terkait dengan topik penelitian.

b. Pengumpulan data, data yang diperlukan adalah data Komentar dari pengguna Twitter yang membahas tentang PSSI (Persatuan Sepakbola Seluruh Indonesia).

c. Analisis data, data komentar yang di kumpulkan dari pengguna twitter yang membahas PSSI kemudian dianalisa berdasarkan kebutuhan penelitian antara lain melakukan pengamatan pada struktur data, kemudian menghitung berapa banyak kata positif dan negatif pada masing-masing komentar secara manual, dan mengamati hasil dari perhitungan dari masing-masing komentar.

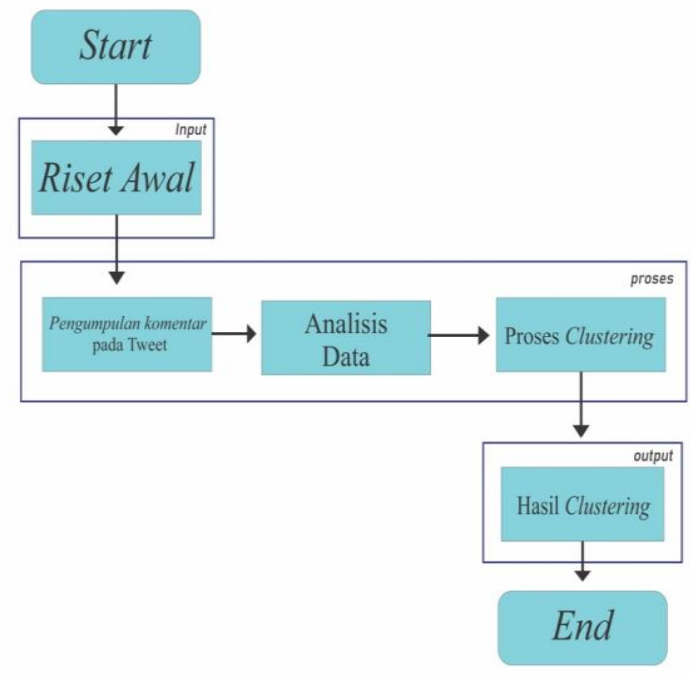

Gambar 1. Tahapan Penelitian

d. Proses clustering, Setelah analisa data, tahap selanjutnya adalah penerapan metode $K$-means Clustering atau pengelompokan jenis komentar pada tweet Pssi berdasarkan nilai kata positif dan kata negatif di setiap komentar. Tahapan proses metode K-Means Clustering dapat dilihat pada Gambar 2 [5].

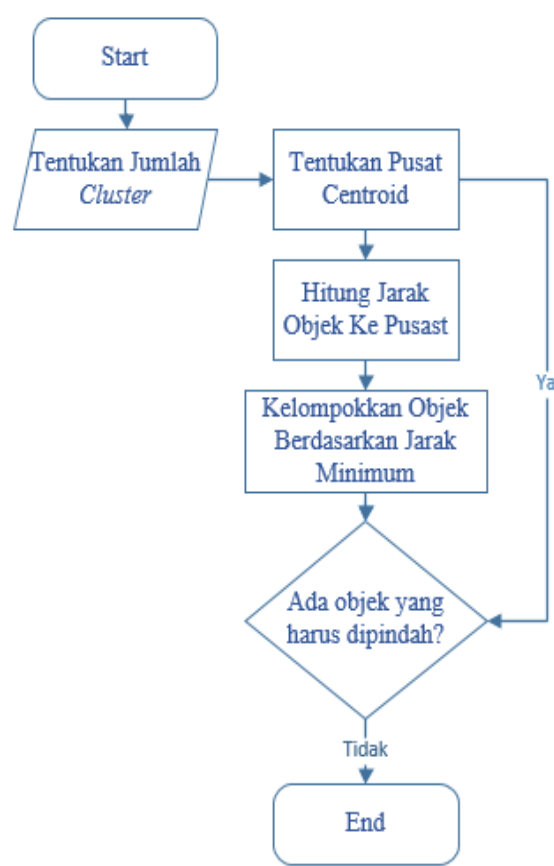

Gambar 2. Flowchart Metode K-means Clustering

e. Pengujian hasil, Setelah selesai melakukan proses pengelompokan dengan menggunakan metode $K$-means, kemudian dilakukan pengujian hasil dengan menganalisis hasil clustering menggunakan Aplikasi Rapid Miner Studio.

\section{HaSil dan PeMbahasan}

3.1. Pengumpulan Data

Data yang digunakan dalam penelitian ini diperoleh atau di ambil secara manual dari komentar pengguna twitter yang membahas PSSI. Jumlah data yang digunakan sebagai bahan penelitian ini adalah 50 data komentar. Pemilihan 50 data ini untuk mempercepat proses perhitungan secara manual dengan microsoft excel. Data komentar yang peneliti peroleh dan dapat dilihat pada Tabel 1.

Tabel 1. Beberapa Data Komentar yang membahas topik PSS

\begin{tabular}{|c|c|}
\hline No & Tweet Komentar \\
\hline 1 & $\begin{array}{l}\text { "@ahmatmarsuki : Mafia itu ADA DAN } \\
\text { NYATA. Selama orang2 itu masih ada di } \\
\text { dalam sepakbola Indonesia dan para } \\
\text { voters masih jadi bebek sepakbola } \\
\text { Indonesia akan hancur. @ PSSI kalian } \\
\text { adalah perusak sepak bola Indonesia }\end{array}$ \\
\hline 2 & $\begin{array}{l}\text { "@abadigunawan : heh tolol ini bukan soal } \\
\text { menang kalah debat. tapi soal keputusan } \\
\text { sepihak yg dikeluarkan PSSI dan nyali } \\
\text { macan jadi kucing. kalau tidak punya otak } \\
\text { gak usah ikut komenlah kau. }\end{array}$ \\
\hline 10 & "@mgl football : Suporter PPSM Magelang \\
\hline
\end{tabular}




\begin{tabular}{|c|c|}
\hline & $\begin{array}{l}\text { Mendapatkan Hukuman Berat Dari } \\
\text { Komdis PSSI }\end{array}$ \\
\hline 11 & $\begin{array}{l}\text { "@Persija_Jkt : Sesuai surat PSSI bernomor } \\
\text { 2709/AGB/536/VII-2019, atas } \\
\text { pertimbangan aspek keamanan dan } \\
\text { kenyamanan pelaksanaan pertandingan } \\
\text { Final Piala Indonesia 2018/2019 Leg } 2 \\
\text { yang sedianya akan berlangsung } \\
\text { 28/7/2019, diputuskan ditunda } \\
\text { pelaksanaannya dengan waktu yang akan } \\
\text { ditentukan kemudian }\end{array}$ \\
\hline$\ldots$ & $\ldots$ \\
\hline 20 & $\begin{array}{l}\text { "@ mulya59 : POIN PENTING NYA adalah : } \\
\text { KONTESTAN PERCAYA SAMA PSSI, } \\
\text { dan PSSI yg percaya para wasit. Ketika } \\
\text { terjadi kontroversi, protes lah ke PSSI, yg } \\
\text { adalah OTORITAS TERTINGGI. } \\
\text { Bukannya protes berlebihan, kemudian } \\
\text { Suporter turun k lapangan, malah } \\
\text { tawuran. Ini mah TOLOL, merusak! }\end{array}$ \\
\hline
\end{tabular}

\subsection{Analisa Data}

Berdasarkan data komentar yang sudah di peroleh dari twitter, kemudian data komentar ini di hitung berapa banyak kata positif dan kata negatif pada setiap data. Hasil perhitungan itu akan digunakan sebagai atribut perhitungan pada penelitian ini.

\subsection{Data Pengujian}

Berikut ini adalah beberapa data tweet komentar PSSI yang berhasil dilakukan perhitungan kata positif dan kata negatif. Hasil perhitungan kalimat positif dan kalimat negatif dapat dilihat pada tabel 2

Tabel 2. Beberapa Data Komentar yang berhasil dilakukan perhitungan kalimat positif dan kalimat

\begin{tabular}{|c|c|c|c|}
\hline No & Tweet & Jumlah * & Jumlah - \\
\hline 1 & $\begin{array}{l}\text { "@ahmatmarsuki : Mafia } \\
\text { itu ADA DAN } \\
\text { NYATA. Selama } \\
\text { orang2 itu masih ada } \\
\text { di dalam sepakbola } \\
\text { Indonesia dan para } \\
\text { voters masih jadi } \\
\text { bebek sepakbola } \\
\text { Indonesia akan } \\
\text { hancur. @PSSI kalian } \\
\text { adalah perusak sepak } \\
\text { bola Indonesia }\end{array}$ & 0 & 3 \\
\hline 2 & $\begin{array}{l}\text { "@abadigunawan : heh } \\
\text { tolol ini bukan soal } \\
\text { menang kalah debat. } \\
\text { tapi soal keputusan } \\
\text { sepihak yg } \\
\text { dikeluarkan PSSI dan } \\
\text { nyali macan jadi } \\
\text { kucing. kalau tidak } \\
\text { punya otak gak usah } \\
\text { ikut komenlah kau. }\end{array}$ & 3 & 4 \\
\hline$\ldots$ & $\ldots$ & $\ldots$ & $\ldots$ \\
\hline
\end{tabular}

\begin{tabular}{|c|c|c|c|}
\hline 10 & $\begin{array}{l}\text { "@mgl_football : Suporter } \\
\text { PPSM Magelang } \\
\text { Mendapatkan } \\
\text { Hukuman Berat Dari } \\
\text { Komdis PSSI }\end{array}$ & 1 & 1 \\
\hline 11 & $\begin{array}{l}\text { "@ Persija_Jkt : Sesuai surat } \\
\text { PSSI bernomor } \\
\text { 2709/AGB/536/VII- } \\
\text { 2019, atas } \\
\text { pertimbangan aspek } \\
\text { keamanan dan } \\
\text { kenyamanan } \\
\text { pelaksanaan } \\
\text { pertandingan Final } \\
\text { Piala Indonesia } \\
\text { 2018/2019 Leg } 2 \text { yang } \\
\text { sedianya akan } \\
\text { berlangsung } \\
\text { 28/7/2019, diputuskan } \\
\text { ditunda } \\
\text { pelaksanaannya } \\
\text { dengan waktu yang } \\
\text { akan ditentukan } \\
\text { kemudian }\end{array}$ & 1 & 0 \\
\hline$\ldots$ & $\ldots$ & $\ldots$ & .. \\
\hline 20 & $\begin{array}{l}\text { "@mulya59 : POIN } \\
\text { PENTING NYA } \\
\text { adalah : } \\
\text { KONTESTAN } \\
\text { PERCAYA SAMA } \\
\text { PSSI, dan PSSI yg } \\
\text { percaya para wasit. } \\
\text { Ketika terjadi } \\
\text { kontroversi, protes } \\
\text { lah ke PSSI, yg adalah } \\
\text { OTORITAS } \\
\text { TERTINGGI. } \\
\text { Bukannya protes } \\
\text { berlebihan, kemudian } \\
\text { Suporter turun k } \\
\text { lapangan, malah } \\
\text { tawuran. Ini mah } \\
\text { TOLOL, merusak! }\end{array}$ & 3 & 3 \\
\hline
\end{tabular}

\subsection{Proses K Means Clustering}

Melakukan langkah langkah perhitungan metode $K$ Means Clustering sesuai dengan Gambar 2.

a. Iterasi 1

1. Tentukan jumlah cluster Jumlah Cluster yang digunakan adalah 3 cluster.

2. Tentukan pusat cluster

Langkah selanjutnya yaitu menentukan pusat cluster, centroid awal dalam proses clustering ini ditentukan dengan aturan. Centroid pertama merupakan hasil rata-rata untuk setiap kriteria pada tabel. Centroid kedua nilai maximum dari setiap kriteria. Centroid ketiga adalah nilai minimum dari setiap kriteria. Sehingga menghasilkan titik awal pusat cluster pada Tabel 3 . 
JUST TI: (Jurnal Sains Terapan Teknologi Informasi) 12, 2 (Juli, 2020):

ISSN: 2579-4510(online) ISSN: 2085-6458(print)

Tabel 3. Titik Awal Pusat Cluster

\section{Titik Awal Pusat Cluster (random)}

\begin{tabular}{ccc} 
Cen1 & 1.8 & 1.76 \\
Cen2 & 6 & 7 \\
Cen3 & 0 & 0 \\
\hline
\end{tabular}

3. Menghitung jarak objek ke pusat cluster terdekat dengan menggunakan Euclidean Distance[6] . Hasil perhitungan dapat dilihat pada Tabel 4.

Tabel 4 Hasil Data Iterasi ke 1

\begin{tabular}{ccccc}
\multicolumn{5}{c}{ Tabel 4 Hasil Data Iterasi ke 1 } \\
$\begin{array}{c}\text { Euclidean Distance } \\
\text { DATA } \\
\text { KE }\end{array}$ & $\mathrm{C} 1$ & $\mathrm{C} 2$ & $\mathrm{C} 3$ & $\mathrm{MIN}$ \\
\hline 1 & 2.19 & 7.21 & 3.00 & 2.19 \\
2 & 2.54 & 4.24 & 5.00 & 2.54 \\
$\ldots$ & $\ldots$ & $\ldots$ & $\ldots$ & $\ldots$ \\
10 & 1.10 & 7.81 & 1.41 & 1.10 \\
11 & 1.93 & 8.60 & 1.00 & 1.00 \\
$\ldots$ & $\ldots$ & $\ldots$ & $\ldots$ & $\ldots$ \\
20 & 1.73 & 5.00 & 4.24 & 1.73 \\
\hline
\end{tabular}

4. Kelompokan objek berdasarkan jarak minimum untuk menentukan anggota cluster. Hasil Pengelompokan dapat dilihat pada Tabel 5.

Tabel 5. Posisi Cluster Iterasi ke - 1

MATRIX KEANGGOTAAN

$\begin{array}{cccc}\text { Data ke } & \text { CLUSTER } & \text { CLUSTER } & \text { CLUSTER } \\ & 1 & 2 & 3\end{array}$

\begin{tabular}{cccc}
\hline 1 & 1 & 0 & 0 \\
2 & 1 & 0 & 0 \\
$\ldots$ & $\ldots$ & $\ldots$ & $\ldots$ \\
10 & 1 & 0 & 0 \\
11 & 0 & 0 & 1 \\
12 & $\ldots$ & $\ldots$ & $\ldots$ \\
20 & 1 & 0 & 0 \\
\hline
\end{tabular}

5. Hitung pusat cluster baru

Setelah semua data ditempatkan kedalam cluster terdekat maka diperoleh hasil dengan jumlah anggota cluster 1 sebanyak 41 data, cluster 2 sebanyak 3 data dan cluster 3 sebanyak 6 data, dari total anggota cluster sebanyak 11. Kemudian langkah berikutnya adalah menghitung pusat cluster yang baru berdasarkan rata-rata angggota yang ada pada cluster tersebut. Sehingga diperoleh pusat cluster iterasi ke - 1 seperti pada Tabel 6 .
Tabel 6. Pusat Cluster Iterasi ke -1

\begin{tabular}{ccc}
\hline \multicolumn{3}{c}{ Pusat } \\
\hline Cluster & Baru \\
\hline Cen1 & 1.73 & 1.66 \\
Cen2 & 5 & 6 \\
Cen3 & 0.67 & 0.33 \\
\hline
\end{tabular}

b. Iterasi 2

Dengan melakukan langkah yang sama pada iterasi ke - 1 diperoleh posisi cluster iterasi ke - 2 seperti yang diberikan pada tabel 7 . Kemudian melakukan perhitungan pusat cluster baru yang akan digunakan pada iterasi ke -3 . Pusat cluster baru dapat dilihat pada table 8 .

Tabel 7. Posisi Cluster Iterasi ke - 2

\begin{tabular}{|c|c|c|c|}
\hline & \multicolumn{3}{|c|}{ MATRIX KEANGGOTAAN } \\
\hline $\begin{array}{l}\text { DATA } \\
\text { KE }\end{array}$ & $\begin{array}{c}\text { CLUSTER } \\
1\end{array}$ & $\begin{array}{c}\text { CLUSTER } \\
2\end{array}$ & CLUSTER 3 \\
\hline 1 & 1 & 0 & 0 \\
\hline 2 & 1 & 0 & 0 \\
\hline$\ldots$ & $\ldots$ & $\ldots$ & $\ldots$ \\
\hline 10 & 0 & 0 & 1 \\
\hline 11 & 0 & 0 & 1 \\
\hline$\ldots$ & $\ldots$ & $\ldots$ & $\ldots$ \\
\hline 20 & 1 & 0 & 0 \\
\hline
\end{tabular}

Tabel 8. Pusat Cluster Iterasi ke -2

\begin{tabular}{ccc}
\hline \multicolumn{3}{c}{ Pusat } \\
Cluster Baru \\
\hline Cen1 & 1.97 & 2.00 \\
Cen2 & 5 & 6 \\
Cen3 & 1.00 & 0.67 \\
\hline
\end{tabular}

c. Iterasi 3

Dengan melakukan langkah yang sama pada iterasi ke -1 diperoleh posisi cluster iterasi ke 3 seperti yang diberikan pada tabel 9. Kemudian melakukan perhitungan pusat cluster baru yang akan digunakan pada iterasi ke - 4. Pusat cluster baru dapat dilihat pada table 10 .

Tabel 9. Posisi Cluster Iterasi ke - 3

\begin{tabular}{cccc}
\hline & & & \\
Data & CLUSTER & CLUSTER & CLUSTER \\
Ke & 1 & 2 & 3 \\
& & & \\
\hline 1 & 1 & 0 & 0 \\
2 & 1 & 0 & 0 \\
$\ldots$ & $\ldots$ & $\ldots$ & $\ldots$ \\
\hline
\end{tabular}




\begin{tabular}{cccc}
\hline 10 & 0 & 0 & 1 \\
11 & 0 & 0 & 1 \\
$\ldots$ & $\ldots$ & $\ldots$ & $\ldots$ \\
20 & 1 & 0 & 0 \\
\hline
\end{tabular}

Tabel 10 Pusat Cluster Iterasi ke - 3

\section{Pusat Cluster Baru}

\begin{tabular}{ccc}
\hline Cen1 & 2.09 & 2.26 \\
Cen2 & 5 & 6 \\
Cen3 & 1.13 & 0.75 \\
\hline
\end{tabular}

\section{d. Iteras1 4}

Dengan melakukan langkah yang sama pada iterasi ke -1 diperoleh posisi cluster iterasi ke -4 seperti yang diberikan pada tabel 12. Kemudian melakukan perhitungan pusat cluster baru yang akan digunakan pada iterasi ke - 5. Pusat cluster baru dapat dilihat pada table 13 .

Tabel 11. Posisi Cluster Iterasi ke -4

\begin{tabular}{cccc}
\hline \multicolumn{4}{c}{ MATRIX KEANGGOTAAN } \\
\hline data ke & CLUSTER & CLUSTER & CLUSTER \\
& 1 & 2 & 3 \\
\hline 1 & 1 & 0 & 0 \\
2 & 1 & 0 & 0 \\
$\ldots$ & $\ldots$ & $\ldots$ & $\ldots$ \\
10 & 0 & 0 & 1 \\
11 & 0 & 0 & 1 \\
$\ldots$. & $\ldots$ & $\ldots$ & $\ldots$ \\
20 & 1 & 0 & 0 \\
\hline
\end{tabular}

Tabel 12. Pusat Cluster Iterasi ke - 4

\begin{tabular}{ccc}
\hline & Pusat Cluster Baru \\
\hline Cen1 & 2.10 & 2.45 \\
Cen2 & 5 & 6 \\
Cen3 & 1.22 & 0.78 \\
\hline
\end{tabular}

\section{e. Iterasi 5}

Dengan melakukan langkah yang sama pada iterasi ke -1 diperoleh posisi cluster iterasi ke - 5 seperti yang diberikan pada tabel 13. Kemudian melakukan perhitungan pusat cluster baru yang ternyata titik pusat tidak lagi mengalami perubahan, sehingga iterasi ke -5 adalah iterasi terakhir. Pusat cluster baru dapat dilihat pada table 14 .

Tabel 13. Posisi Cluster Iterasi ke -5

\begin{tabular}{cccc}
\hline \multicolumn{4}{c}{ MATRIX KEANGGOTAAN } \\
\hline data ke & CLUSTER & CLUSTER & CLUSTER \\
& 1 & 2 & 3 \\
\hline 1 & 1 & 0 & 0 \\
2 & 1 & 0 & 0 \\
$\ldots$ & $\ldots$ & $\ldots$ & $\ldots$ \\
10 & 0 & 0 & 1 \\
11 & 0 & 0 & 1 \\
$\ldots$ & $\ldots$ & $\ldots$ & $\ldots$ \\
20 & 1 & 0 & 0 \\
\hline
\end{tabular}

Tabel 14 Pusat Cluster Iterasi ke - 3

\begin{tabular}{ccc}
\hline & Pusat Cluster Baru \\
\hline Cen1 & 2.10 & 2.45 \\
Cen2 & 5 & 6 \\
Cen3 & 1.22 & 0.78 \\
\hline
\end{tabular}

f. Hasil Clustering

Berdasarkan hasil pengelompokan data menggunakan metode $K$-means clustering yaitu mencapai hasil clustering hingga iterasi ke - 5, dimana titik pusat tidak lagi berubah dan tidak ada data yang berpindah antar cluster. Dari hasil perhitungan didapatkan 3 kelompok cluster atau centroid yaitu:

1. Cluster yang pertama memiliki pusat cluster $(2.10 ; 2.45)$

2. Cluster yang kedua memiliki pusat cluster $(5 ; 6)$

3. Cluster yang ketiga memiliki pusat cluster $(1.22 ; 0.78)$

4. Pada perhitungan iterasi ke - 4 dan ke -5 jarak terdekat pengelompokan jarak minimum objek yang termasuk kategorinya sebagai berikut : cluster pertama terdapat (20 data komentar), cluster kedua terdapat (3 data komentar ), dan cluster ke 3 (27 data komentar ).

5. Hasil clustering kemudian di Persentasekan pada Gambar 3 untuk melihat jenis komentar manakah yang mendominasi. Pada penelitian ini Jenis komentar ironi mendominasi dengan 54\% kemudian jenis komentar sinisme dengan $40 \%$ dan komentar sarkasme dengan $6 \%$. 


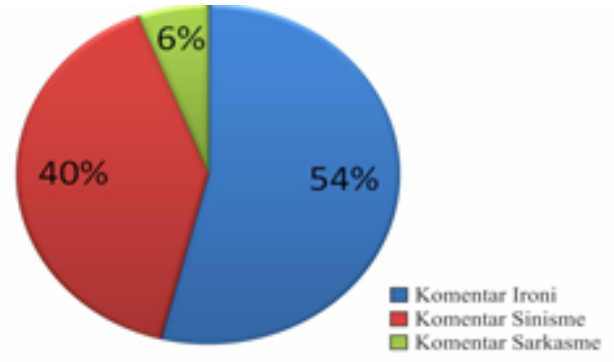

Gambar 3. Persentase Jenis Komentar

\subsection{Pengujian Hasil}

Setelah melakukan perhitungan manual metode $K$-means Clustering dengan menggunakan Microsoft Excel selanjutnya peneliti melakukan pengujian hasil clustering dengan menggunakan aplikasi Rapid Miner. Pengujian dilakukan dengan menggunakan data berjumlah 50 data komentar yang memiliki 2 atribut yaitu jumlah kalimat positif dan jumlah kalimat negatif. Hasil yang didapat setelah melakukan pengujian menggunakan aplikasi Rapid Miner dapat dilihat pada Gambar 4.

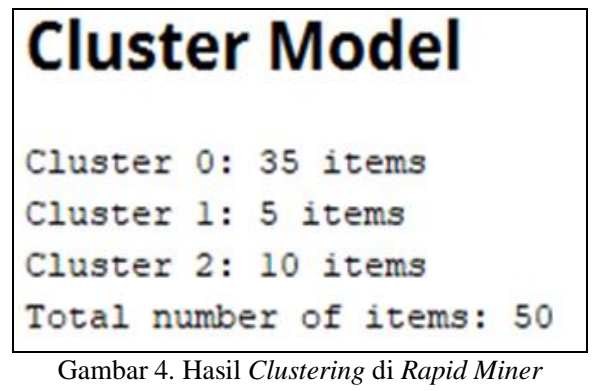

\section{KESIMPULAN}

Berdasarkan hasil penelitian yang telah dilakukan, diperoleh kesimpulan bahwa :

1. Pengujian yang dilakukan dalam penelitian ini, terjadi iterasi sebanyak 5 kali iterasi.

2. Dari proses perhitungan menggunakan metode $K$-Means clustering menghasilkan :

a. Kelompok Jenis komentar sinisme pada cluster 1 sebanyak 20 data komentar.

b. Kelompok Jenis komentar sarkasme pada cluster 2 sebanyak 3 data komentar.

c. Kelompok Jenis komentar ironi pada cluster 3 sebanyak 27 data komentar.

3. Perhitungan K-Means Clustering dalam penelitian ini memiliki perbedaan hasil dengan hasil perhitungan pada aplikasi RapidMiner. Di karenakan pada penelitian ini, untuk penentuan Centroid awal. Peneliti menggunakan nilai rata-rata, nilai maximum dan nilai minimum.
4. Hasil Akhir Cluster juga dipengaruhi dari nilai centroid awal yang digunakan dan jumlah data yang dipakai.

\section{REFERENSI}

[1] Sugono, D. et al .2008. Kamus Besar Bahasa Indonesia (Edisi Keenam). Jakarta: PT Gramedia Pustaka Utama.

[2] Keraf, G. 2006. Diksi dan Gaya Bahasa (Edisi yang) Disempurnakan. Jakarta: PT Gramedia Pustaka Utama.

[3] Tarigan, H. G. 2009. Pengajaran Gaya Bahasa (Edisi Revisi). Bandung: Percetakan Angkasa

[4] Ong, J. O. "Implementasi Algotritma K-means clustering untuk menentukan strategi marketing president university". Jurnal Ilmiah Teknik Industri, Vol. 12, No. 1, Juni 2013.

[5] Nasari, F., dan Darma, S. 2015. Penerapan $K$ Means Clustering Pada Data Penerimaan Mahasiswa Baru. Seminar Nasional Teknologi Informasi Dan Multimedia 2015, 73-78.

[6] Azis, W.S., dan Atmajaya, D. 2016, Pengelompokan Minat Baca Mahasiswa menggunakan Metode K-Means. ILKOM Jurnal Ilmiah, 892), 89. 